\title{
MARÍA JOAQUINA VIERA Y CLAVIJO, JOSEFA DE MIRANDA Y JUANA EVANGELISTA DE LA CRUZ Y RÍOS: MUJERES EN LA ACTIVIDAD ARTÍSTICA DEL SIGLO XVIII EN CANARIAS
}

\author{
Yolanda Peralta Sierra \\ Universidad de La Laguna \\ yperalta@ull.edu.es
}

\section{RESUMEN}

\begin{abstract}
Al abordar el estudio de la mujer en la creación artística en Canarias en el siglo xviıI, a la escasez de referencias bibliográficas y documentales hay que unir la dificultad para localizar sus obras artísticas. A pesar de ello, han sido hallados los nombres y algunas referencias biográficas de mujeres que llevaron a cabo actividades en el ámbito artístico canario en esta centuria, como María Joaquina Viera y Clavijo, Josefa Miranda y Juana Evangelista de la Cruz y Ríos.
\end{abstract}

Palabras Clave: mujeres artistas, siglo XVIII, educación artística, Canarias.

\author{
MARÍA JOAQUINA VIERA Y CLAVIJO, JOSEFA DE MIRANDA \\ AND JUANA EVANGELISTA DE LA CRUZ Y RÍOS: WOMEN \\ IN ARTISTIC ACTIVITY IN THE 18TH CENTURY \\ IN THE CANARY ISLANDS
}

Abstract

When approaching to the study on women's artistic creation in Canary Islands for eighteenth century, the lack of bibliographical and documented references has to be added to the difficulty on finding their artistic works. In spite of it, we found the names and bibliographic references about women who carried on artistic activities in Canary Islands during the century, such as the case of María Joaquina Viera y Clavijo, Josefa Miranda and Juana Evangelista de la Cruz y Ríos.

KeYwords: Artist women, century XviII, Artistic Education, Canary Islands. 


\section{INTRODUCCIÓN: \\ LA EDUCACIÓN FEMENINA EN EL SIGLO DE LAS LUCES}

La participación de las mujeres en la actividad artística del siglo XvinI en Canarias se desarrolla en un contexto en el que el dibujo y la pintura formaban parte de la educación femenina. En esta centuria eran pocas las féminas que sabían leer y escribir, en su mayoría pertenecientes a la aristocracia, las únicas que podían acceder a una educación básica. Las mujeres de los sectores populares, por el contrario, no recibían instrucción y se dedicaban al cuidado de los hijos e hijas y a las labores agrícolas. Sólo algunas mujeres de zonas urbanas realizaban labores manuales, principalmente trabajos de aguja, quedando relegada a un segundo plano para ellas la alfabetización.

A partir de la segunda mitad del siglo XviII la instrucción femenina adquirió relevancia, llegando a convertirse en un tema no exento de polémica. Las opiniones a favor de la educación de las féminas se fundamentaban en la creencia en que la adquisición de una instrucción elemental no contradecía el mantenimiento de su papel tradicional en la sociedad y que incluso podía mejorar su tarea como educadoras de los hijos e hijas. Para las niñas de clases elevadas, la educación femenina era considerada un adorno y debía proporcionar una formación básica compuesta por labores domésticas, religión, moral, urbanidad, rudimentos de lectura y escritura, algunas nociones de gramática, literatura, historia, filosofía y algo de baile, canto y música.

Durante el reinado de Carlos III fueron adoptadas una serie de iniciativas oficiales orientadas a mejorar la enseñanza femenina (Monzón Perdomo y Santana Pérez 1990). Así, la Real Cédula de 1768 estableció que la educación no debía restringirse a los niños, sino que debía impartirse también a las niñas (González Pérez 1998). Años después, en 1783, a través de otra Real Cédula fueron creadas las Escuelas de Barrio para niñas de familias humildes, pues hasta esa fecha no existían escuelas públicas en España.

Las medidas para mejorar la educación de las mujeres fueron promovidas por entidades privadas como las Sociedades Económicas de Amigos del País, que abrieron establecimientos dedicados en su mayor parte al aprendizaje del arte de hilar, considerada la profesión idónea para las mujeres. Las principales figuras ilustradas en España, como Benito Jerónimo Feijoo, Gaspar Melchor de Jovellanos, el conde de Campomanes o el conde de Floridablanca, se ocuparon en sus obras de la enseñanza de las féminas. En sus escritos reflexionaron sobre la educación femenina, trasladando este debate a la opinión pública. Jovellanos consideraba que las mujeres tenían la misma capacidad de raciocinio que los hombres, pero la educación había marcado las diferencias entre ambos sexos. En este aspecto resultan esclarecedoras sus opiniones en el Informe dado a la Junta General de Comercio y moneda sobre el libre ejercicio de las artes (1785) (Melchor de Jovellanos, 1952), elaborado con el objetivo de acometer una reforma de las ordenanzas gremiales de artes y oficios. En este texto Jovellanos insiste en que había sido la tradición y el sexo masculino los que habían llevado a la mujer del siglo xviII al estado de deterioro intelectual y moral que la caracterizaba. En este informe critica además que la legislación gre- 
mial hubiera impuesto «cadenas a las mujeres para ejercer oficios». En este sentido, las Reales Cédulas establecían como regla general que a las mujeres les estaba permitido realizar todos los trabajos que fueran propios de su sexo, aunque ni la Real Cédula de 1779 ni la Real Cédula de 1784 señalaban, en opinión de Jovellanos, de forma específica las manufacturas que podían realizar las mujeres.

El objetivo del informe es por tanto averiguar cuáles son «los trabajos que repugnan a la decencia y fuerzas mujeriles». Su autor concluye que no pueden reconocerse cuáles son las artes que repugnan a la decencia del sexo femenino porque las ideas de decencia dependen de la época, de los estados y del estamento social al que pertenezca la mujer, aunque considera que las artes fáciles y sedentarias son las más convenientes para la mujer. Añade además que las féminas han sido sistemáticamente excluidas de los gremios de forma injusta porque «ha separado casi enteramente a las mujeres del ejercicio de las artes», reduciendo a la "ociosidad unas manos que la naturaleza había criado diestras y flexibles para perfeccionar el trabajo». Propone, asimismo, que la legislación tenga en cuenta la necesidad de «formar una matrícula general de cada arte, en la cual se asentarán los nombres de los que la profesan, sean hombres o mujeres, con especificación de su edad, estado y de la clase que ocupan en el arte; esto es, de maestros con tienda u obrador público, oficiales sueltos, o aprendices».

El pensamiento ilustrado y las nuevas ideas pedagógicas del Siglo de las Luces van a manifestarse en Canarias a partir de la segunda mitad del siglo XVIII (González Pérez 1998). A finales de la centuria los ilustrados canarios empiezan a reflexionar sobre la enseñanza femenina, reflexiones teóricas que en última instancia no se llevaron a la práctica. La educación femenina en Canarias no se basó en la alfabetización, sino en afianzar el papel de la mujer dentro de la sociedad patriarcal, relegando su función al orden doméstico y reforzando en las niñas su papel de encargadas del hogar y de la familia. En Tenerife, a finales del siglo XVIII, algo más de la mitad de la población escolar femenina recibía algún tipo de instrucción, contando la isla con 31 núcleos habitados en 16 de los cuales se impartía enseñanza a niñas, siendo la zona norte, más poblada, la que más áreas escolarizadas presentaba. En Gran Canaria existían pocas escuelas, en su mayoría dirigidas a la educación de los niños. Como es de suponer, el índice de analfabetismo femenino era superior al masculino para el conjunto de las islas.

\section{LAS MUJERES EN LOS CÍRCULOS ILUSTRADOS}

Como en otros países europeos, en España a finales de la Edad Moderna van a introducirse debates en torno a la naturaleza y a la condición de la mujer que anunciaban ya ciertos cambios relativos a su consideración social y a su proyección en el ámbito de lo público. En algunos de los círculos en los que se propagó el pensamiento ilustrado participaron mujeres que vieron en las nuevas ideas una plataforma para poder proyectar sus inquietudes, tanto intelectuales como sociales. La nueva coyuntura propiciada por la Ilustración facilitó a algunas mujeres de las élites su incorporación a los círculos culturales y su participación en las nuevas corrientes 
de pensamiento, constatándose un aumento en el número de escritoras que, a través de sus textos, van a reflexionar sobre sus condiciones de vida. Algunas de ellas se adentraron en el espacio de lo público, tradicionalmente reservado a los hombres, desarrollando profesiones y actividades culturales, e incorporándose a los círculos oficiales del arte (Martínez López 1999).

En este contexto dejaron oír su voz mujeres que participaron en los debates contemporáneos. Entre esas figuras femeninas ilustradas en España cabe destacar a Josefa Amar y Borbón (Zaragoza, España, 1749-1833). Hija del médico de Cámara de Fernando VI y conocida traductora, defendía en sus escritos la importancia de la instrucción femenina. En 1790, en su Discurso sobre la educación física y moral de las mujeres, resaltó la cuestión educativa denunciando que las propias féminas prestaban escasa atención al aprendizaje porque su educación era considerada una materia de poca entidad. Con sus textos se propuso rescatar de la ociosidad a las mujeres, animándolas para que realizaran trabajos útiles (hilados, cordonería, botonería...) para contribuir al incremento de la productividad nacional y paliar los problemas de la Real Hacienda (Aguado et al. 1994). Para Josefa Amar y Borbón la música y el dibujo eran dos habilidades que recomendaba practicar a las féminas:

El dibujo y la música tienen su mérito particular; y no se puede ser eminente en ellas sin un cierto grado de ingenio, de invención y de delicadez de gusto poco común. [...] El dibujo tiene las mismas y mayores ventajas que la música para entretener la imaginación y empeñarla a nuevos progresos. Se practica muy bien en la soledad, y es bastante para contentar el ánimo cuando se ha hecho una obra perfecta. Son muchas las circunstancias que reúne para hacerlo recomendable, como son el estudio de las principales reglas, la imitación de la naturaleza tan varia en sus producciones, la inteligencia en la historia verdadera y fabulosa, las diversas aptitudes, la mezcla y cantidad de los colores; y sobre todo, la propiedad de lo que intenta representarse, que viene a ser como el alma de la pintura, que distingue los grandes ingenios de los medianos. El dibujo conduce para las labores de manos, porque da la verdadera idea de la figura y la proporción de las cosas [...]. Nadie ignora que es infinito el número de las mujeres que se ha distinguido en la pintura, y debiera desearse que se extendiera esta afición, por ser un ejercicio muy honesto (Amar y Borbón 1994).

Josefa Amar y Borbón fue contemporánea de algunas artistas de reconocido talento como Ana María Mengs (Dresde, Alemania, 1751-Madrid, España, 1792), María de Loreto Prieto (Madrid, España, 1753-Segovia, España, 1772), Dorotea Michel o María Waldstein. Sin embargo, aun reconociendo que hubo muchas mujeres pintoras, consideraba que la pintura y el dibujo eran aficiones, como otras muchas, recomendables para la mujer, siendo sus verdaderas ocupaciones «el cuidado de la casa y la ilustración del entendimiento» (Amar y Borbón 1994).

La afición por los libros y la cultura también penetró en las mujeres isleñas de familias acomodadas. Las que poseían cierto estatus socioeconómico recibían una educación que en la mayoría de los casos se reducía a la que se impartía en los conventos. A pesar de las dificultades, destacaron mujeres pertenecientes a los sectores acomodados de la sociedad insular, procedentes de núcleos aristocráticos, como 
María de Bethencourt y Molina, monja clarisa del Puerto de la Orotava; la marquesa de Villanueva del Prado; la abadesa Rosa del Sacramento Jiménez; la maestra hilandera María de León; la religiosa del convento de Santa Catalina de La Orotava y poeta Josefa del Sacramento (González Pérez 1998); o la poeta y escultora María Joaquina Viera y Clavijo (Fraga González 1985-1987).

\section{MUJERES ARTISTAS: MARÍA JOAQUINA VIERA Y CLAVIJO, JOSEFA DE MIRANDA Y JUANA EVANGELISTA DE LA CRUZ Y RÍOS}

El creciente número de mujeres pertenecientes a familias acomodadas con inquietudes artísticas puede explicarse por la emergente incorporación de la pintura y el dibujo a los contenidos de la educación femenina y por las nuevas corrientes ideológicas, que abogaban por una instrucción entendida como adorno de las damas y, en cierta medida, como un medio de controlar su papel como esposas y madres en la sociedad. Las obras artísticas realizadas por estas mujeres eran un ornato de su educación y un tipo de entretenimiento no problemático, teniendo como maestro a algún pintor o artista de renombre o de segunda fila. Otras se formaron en el taller familiar con maridos, padres o familiares cercanos.

Con veinte años de edad, María Joaquina Viera y Clavijo (1737-1819) se traslada con su familia a La Laguna, ciudad en la que entra en contacto con el ambiente ilustrado, a través de su hermano, el historiador y poeta José Viera, estableciendo relación con aristócratas como Tomás de Nava Grimón y Porlier, v marqués de Villanueva del Prado, o Lope Antonio de la Guerra y Peña. Recibió enseñanzas artísticas del escultor y pintor José Rodríguez de la Oliva (1695-1777), siendo sus únicas obras conocidas los retratos escultóricos de personajes eclesiásticos de su entorno como el obispo Juan Bautista Cervera, el padre Facenda y Vicente Ramos. Otra de sus obras documentadas es un Ecce Hommo en una urna de cristal que en su testamento legó a su sobrina Da Micaela Ginory (Fraga González 1985-1987). Estos bustos y pequeńas figuras con las efigies de miembros de la sociedad lagunera realizados por María Joaquina Viera y Clavijo se insertan en un contexto en el que no era habitual la producción de estatuaria de tipo laico.

¿Qué opiniones suscitaba entre sus coetáneos la dedicación de una mujer a la escultura en el ambiente ilustrado de La Laguna? El v marqués de Villanueva del Prado, Tomás de Nava Grimón y Porlier, en una carta dirigida a José de Viera y Clavijo, cuando este se hallaba en Madrid, le informa acerca de los progresos de su hermana María en el modelado de la figura humana en barro, calificando sus retratos escultóricos de "obra prima en su género» y recogiendo asimismo las opiniones de su maestro José Rodríguez de La Oliva, apodado el Moño Viejo:

Su familia de Vmc. prosigue sin novedad; una de las señoritas sus hermanas ha dado a luz en estos días (no se asuste Vmc) las pequeñas estatuas del P. Facenda y de Dn. Vicente Ramos. Son una obra prima en su género, y el «Moño Viejo» asegura que deben de tener tanta estimación como los mejores productos de su pincel. Dice que como esta Dama le haga un retrato, él le hará otro (Padrón Acosta 1943). 
La propia María Joaquina, en unos versos dedicados a José Rodríguez de la Oliva, manifiestó su total admiración hacia este, tildando sus trabajos escultóricos de pueriles comparados con los de su maestro:

Del célebre Rodríguez el pincel / excede en infinito a mi buril. / En lienzo con primores obra él, / yo trabajo sin arte en barro vil. / Al lado de su copia exacta y fiel, / mi escultura parecerá pueril. / En conclusión: él llevará la palma, / pues yo retrato el cuerpo, y él el alma (Padrón Acosta 1943).

En su producción tanto escultórica como lírica influyó el ambiente familiar con sus dos hermanos sacerdotes, José y Nicolás. Escribió poesías satíricas, contra Godoy, encomiásticas como las dirigidas a Luis de la Encina y La Perla y a su hermano José de Viera y patrióticas como la compuesta para fomentar el patriotismo de las damas en 1808. En torno a 1780 trasladó su residencia a Las Palmas de Gran Canaria, ciudad en la que su hermano formaba parte de la curia catedralicia. Falleció en el año 1819 en su casa de la plaza de Santa Ana.

Josefa de Miranda (¿? -1771) fue otra de las artistas de esta centuria, cuyo ejemplo se corresponde con el de una mujer que se dedicó profesionalmente al arte. La historiadora del arte Margarita Rodríguez González, en su estudio sobre su hermano, el también pintor Juan de Miranda (1723-1805), nos ofrece algunos datos sobre ella:

Juan no fue el único artista de la familia Miranda, pues su hermana Josefa se dedicó a "pintar y copiar", pero no como un mero entretenimiento sino como una fuente de ingresos [...]. Así se indica en la escritura por la que su madre y hermanos le ceden la casa familiar de la calle Triana (en Las Palmas de Gran Canaria), pues con el producto de su trabajo se ofrece a pagar las deudas tributarias que tiene el inmueble (Rodríguez González 1994).

Creció en un ambiente familiar caracterizado por las múltiples vinculaciones de sus ascendientes Francisco de Miranda y Josefa de Sejas con el mundo artístico de la época. En la partida de matrimonio de estos constan como testigos «Francisco de Torres, pintor establecido en Gran Canaria a finales del siglo xviI, Blas de Anchieta, padre del pintor Ventura de Anchieta, y Francisco de Paula Facenda, testigo en el matrimonio de Francisco, esclavo del tallista y pintor Alonso Ortega" (Concepción Rodríguez 1995). Se ha especulado acerca de la posibilidad de que Juan de Miranda tuviera como referente a su hermana, que mantuvo contactos con José de San Guillermo, considerado uno de los maestros de José Luján Pérez, testigo además de su testamento otorgado en Las Palmas de Gran Canaria el 2 de julio de 1771 (Rodríguez González 1994).

Otras mujeres se formaron en el taller familiar ayudando a sus parientes masculinos. Es el caso de Juana Evangelista de la Cruz y Ríos (1780-1808), hija del pintor Manuel Antonio de la Cruz y de Juana Josefa Nepomuceno Ríos y Camacho. Junto a su hermano Luis Paulino aprendió el arte de la pintura y las diversas técnicas y procedimientos artísticos en el taller que su padre tenía en el Puerto de la Cruz, ayudando a este a dorar y a pintar esculturas. Pero mientras su hermano Luis 
de la Cruz hizo público su trabajo, con el reconocimiento general, Juana Evangelista realizó su labor de ayudante, elaborando sus obras de forma soterrada y oculta. Se trata por tanto de un ejemplo de labor modesta y callada llevada a cabo por mujeres en el contexto artístico del taller familiar.

No sobresalió, por lo menos públicamente, en la escultura o en la pintura, pero sí destacó en una actividad tradicionalmente asociada a la feminidad más estereotipada y que en esta época realizaban los varones: el bordado․ Bajo las nuevas ideas pedagógicas de la Ilustración se justificó la intervención de las mujeres en el trabajo del bordado. Hasta la época de Carlos III no se produce en España la incorporación de las mujeres al ámbito de los oficios artísticos, y más concretamente en el ramo textil. Dicha incorporación se vio favorecida por la puesta en marcha de medidas liberalizadoras como las Reales Cédulas del 12 de enero de 1779 y del 2 de septiembre de 1784, que establecían la participación femenina en «todas aquellas labores y artefactos que son propios de su sexo", como hilados, cordonería, pasamanería, encajes, bordados y costura, actividades que hasta ese momento eran llevadas a cabo exclusivamente por hombres en el ámbito gremial (López Castán 1997). En Canarias, durante el siglo XviI, como explica el profesor Jesús Pérez Morera en su estudio sobre el arte de la seda:

... la hechura y confección de los ornamentos (corte y unión de las piezas de tela; colocación de complementos bordados y pasamanerías) fue tarea, en un principio masculina, realizada por sastres y bordadores y, con frecuencia, por otros artistasartesanos (carpinteros, escultores y pintores) que compaginaron su trabajo con estos menesteres [...]. Sin embargo, a partir del siglo xvIII, esta labor fue pasando progresivamente a manos femeninas, hasta el punto que, con el tiempo, se consideró trabajo exclusivamente de mujeres [...]. En las casas aristocráticas, las mujeres se dedicaban a bordar y confeccionar ornamentos para el culto, como forma de exteriorizar su devoción y su posición social [...]. Asimismo, el bordado y las labores de pasamanería se cultivaban en los conventos de monjas de clausura (Pérez Morera 2002).

En el siglo Xviı la producción de seda en las islas fue muy abundante, existiendo dentro del ramo textil dos modalidades bien diferenciadas: los tejedores «de lo ancho" y los tejedores dedicados a obras menores. Procedentes la mayoría de ellos de la Península a instancias de entidades o particulares, los tejedores «de lo ancho» tejían tafetanes, terciopelos y rasos en talleres en los que también vendían sus productos al público. Los tejedores de obras menores de seda se dedicaban al tejido de cintas, galones, medias o guantes. Se trataba de labores de carácter doméstico realizadas normalmente por mujeres que se encargaban de la preparación de la fibra, del proceso de teñido y de la tejeduría y que vendían sus productos de forma ambu-

${ }^{1}$ En el siglo xvi el bordado era una actividad típicamente masculina. El bordador realizaba el bordado tanto de los vestidos como el de las ropas de culto. Las damas de alta alcurnia y también los caballeros eran aficionados a la realización de bordados. Citemos como ejemplos al rey Carlos IV y a su hermano el infante don Antonio Pascual de Borbón. 
lante (Cruz 1995). En este contexto el bordado (Santana Rodríguez 2002) era una actividad desempeńada por los gremios, pero también realizada en el ámbito doméstico y familiar. Las mujeres realizaban labores de bordado, bien como actividades subalternas de colaboración y ayuda en el taller de la familia dirigido por un hombre, o bien como actividad de ocio entre las clases acomodadas. De la dedicación a la pintura, al dorado de escultura y al bordado de Juana Evangelista nos proporcionan información algunos testimonios literarios recogidos por la historiadora del arte Clementina Calero Ruiz en un estudio sobre Manuel Antonio de la Cruz. En una carta fechada en Tegueste el día 8 de febrero de 1854 dirigida a Antonio Pereyra Pacheco y Ruiz, cura de Tegueste, Agustín Álvarez Rixo señala que Manuel de la Cruz: «tenía una hija llamada Juanica, que se casó con el escribano Henríquez en Santa Cruz y murió ética del mucho atarearse al bordado de oro, tul; y ésta de un carácter amabilísimo, le ayudaba a dorar y preparar las esculturas para el colorido (...)». (Calero Ruiz 1982)

En otra carta enviada a Álvarez Rixo fechada el 15 de mayo de 1855, Pereyra escribe: «(...) su hija Juanica que casó con el Escrib ${ }^{\circ}$ Enríquez en Sta. Cruz y murió joven de resultas de sus tareas de bordar, dorar y pintar (...)» (Calero Ruiz 1982).

En su diario, Juan Primo de la Guerra, el vizconde de Buen Paso, hace referencia a un chaleco bordado por Juana Evangelista, refiriéndose a ella como una "célebre artista»: "mi hermana me ha enviado a bordar un chaleco a casa de una célebre artista que vive a la sazón en La Laguna y hermana del pintor don Luis Paulino, oficial de artillería. Que los petrimetres usan una especie de sayos o trajes de comodidad, que llaman levitas» (Primo de la Guerra 1800-1807, citado por Calero Ruiz 1982).

Escribe el vizconde en otra de las páginas de su diario: «Ayer por la mañana recibí el chaleco que me ha bordado la hija del pintor don Manuel de la Cruz y lo di a hacer para estrenarlo en estos días» (Primo de la Guerra 1800-1807, citado por Calero Ruiz 1982).

En el año 1802 contrae matrimonio con el escribano Enrique Josef Rodríguez (Peralta Sierra 2006), matrimonio que durará seis años, pues Juana Evangelista de la Cruz y Ríos fallece en La Laguna en 1808 (Peralta Sierra 2006) a los veintiocho años de edad. Como relata el vizconde:

Ha muerto en La Laguna en los últimos días de septiembre dońa Juana de la Cruz, hermana del oficial de Artillería don Luis Paulino de la Cruz y mujer del escribano don Enrique Josef Rodríguez. Esta joven era de buen aspecto y sobresaliente en el bordado; en estas memorias que tengo hecha mención de su habilidad. Yo la he visto por última vez en su casa de Santa Cruz en la mañana del 24 de julio próximo (Primo de la Guerra 1808-1810, citado por Calero Ruiz 1976). 


\section{CONCLUSIONES}

Durante el siglo XVIII las mujeres accedían a la formación artística en ambientes ilustrados, como María Joaquina Viera y Clavijo, o en el taller familiar con algún pariente varón, como Josefa de Miranda y Juan Evangelista de la Cruz y Ríos. A estos nombres hay que sumarles otros, como el de la pintora Paula Travieso. De ella sabemos que era vecina de Arucas, en Gran Canaria, y que el 20 de mayo de 1749 recibió 20 reales en pago por la recomposición de un cuadro que había pertenecido a Pedro José Cabrera Linzaga, declarando en un documento no saber firmar (Concepción Rodríguez 1995).

En la recuperación y rescate de las mujeres artistas del pasado, las partidas de defunción proporcionan una valiosa información. En estos documentos se constata la existencia de mujeres a las que se hace referencia como «la pintora». Así, han sido localizados los nombres de Juana «la pintora», enterrada el 2 de enero de 1734 en la capilla del Carmen de la iglesia de Nuestra Señora de los Remedios de La Laguna (Rodríguez González 1987); Mariquita «la pintora», hija de don Jorge Serón, enterrada el 27 de julio de 1771 en La Laguna (Peralta Sierra 2006); Francisca «la pintora», vecina de La Laguna, viuda que falleció a los ochenta años el 17 de septiembre de 1771 (Rodríguez González 1987); y Nicolasa, pintora, viuda del alférez Jerónimo Cabrera; fallecida el 9 de septiembre de 1768 (Rodríguez González 1987).

Un estudio más profundo de la documentación conservada en los archivos de Canarias ayudaría a suministrar información para reconstruir y elaborar las biografías y trayectorias de las mujeres que participaron en la actividad artística del siglo XVIII en Canarias, conocer qué tipo de obras realizaron y, en el mejor de los casos, su paradero actual. Todo ello contribuiría, sin duda, a trazar un panorama histórico general de la presencia de las mujeres en el arte en Canarias.

Enviado: 8 de noviembre de 2021; ACEPTADo: 11 de noviembre de 2021 


\section{BIBLIOGRAFÍA}

Aguado, A.M., Capel, R.M., Matínez López, C., Nash, M., Nielda, G., Ortega, M., Pastor, R., Ramos, M.D., Rodríguez Galdo, M.X., Tavera, S., Ugalde, M. (1994). Estudios de las Mujeres, Feministas y de Género. Madrid: Ediciones Cátedra, pp. 29-30.

Calero Ruiz, C. (1982). Manuel Antonio de la Cruz, pintor portuense (1750-1809). Puerto de la Cruz: Aula de Publicaciones del Ayuntamiento del Puerto de la Cruz.

Concepción Rodríguez, J. (1995). Patronazgo artístico en Canarias durante el siglo XVIII. Las Palmas de Gran Canaria: Ediciones del Cabildo Insular de Gran Canaria, p. 352.

De la Cruz Rodríguez, J. (1995). Textiles e indumentarias de Tenerife. Santa Cruz de Tenerife: Cabildo de Tenerife, CajaCanarias.

Fraga González, C. (1985-1987). «María Viera y Clavijo en el ambiente artístico de los ilustrados en Canarias». El Museo Canario, Las Palmas de Gran Canaria: El Museo Canario, n. XLVII, pp. 319-333.

González Pérez, T. (1998). Mujer y educación en Canarias: anotaciones históricas. Santa Cruz de Tenerife: Cabildo Insular de Tenerife, Benchomo.

López Catalán, Á. (1997). "Las escuelas femeninas de encajes en el Madrid ilustrado». VIII Jornadas de Arte. La mujer en el Arte Español. Madrid: Alpuerto.

Margarita Rodríguez, G. (1994). Juan de Miranda. Santa Cruz de Tenerife: Servicio de Publicaciones de la Caja General de Ahorros de Canarias.

Martínez López, C. (1999). «La Historia de las mujeres en España en los años noventa», en VV.AA. Universidady feminismo en España (II). Situación de los Estudios de las mujeres en los años 90, Colección Feminae. Granada: Universidad de Granada, pp. 271-273.

Melchor de Jovellanos, G. (1952). «Informe dado a la Junta General de Comercio y moneda sobre el libre ejercicio de las artes», en Obras publicadas e inéditas de Don Gaspar Melchor de Jovellanos, Biblioteca de Autores Españoles. Desde la formación del lenguaje hasta nuestros días, tomo II. Madrid: Atlas, pp. 33-45.

Monzón Perdomo, M.A. y Santana Pérez, J.M. (1990). "Instrucción femenina en Canarias durante el reinado de Carlos III». Actas del Coloquio Internacional Carlos III y su Siglo, vol. 2. Madrid: Universidad Carlos III de Madrid, pp. 737-754.

Padrón Acosta, S. (1943). «La Personalidad artística de D- José Rodríguez de la Oliva (1695-1777)». Revista de Historia, n. 61, pp. 14-29

Peralta Sierra, Y. (2006). Mujer y arte en Canarias: mujeres creadoras e iconografías femeninas. Tesis doctoral inédita. La Laguna: Universidad de La Laguna.

Pérez Morera, J. (2002). «El arte de la seda. El tejido en Canarias. Los ornamentos de la Catedral de La Laguna». Revista de Historia Canaria, n. 184, pp. 283-284.

Rodríguez González, M. (1987). «Pintoras doradoras tinerfeñas. Ana Francisca». Actas del VI Coloquio de Historia canario-americana, tomo II. Las Palmas de Gran Canaria: Cabildo Insular de Gran Canaria, pp. 345-352.

Santana Rodríguez, L. 2002. "Los bordados en Tenerife durante el siglo Xvi». Estudios Canarios. Anuario del Instituto de Estudios Canarios, n. XLVI, pp. 493-503. 